\title{
The effect of clomiphene on parturition and post-partum ovulation in rats
}

\author{
K. Hashizume, S. Sugawara and S. Takeuchi \\ Laboratory of Animal Reproduction, Faculty of Agriculture, Tohoku University, Sendai, Japan
}

We have previously described studies of parturition and subsequent reproductive phenomena in rats which showed that the time of the LH surge and post-partum ovulation are related to the time of parturition (Hashizume, Sugawara \& Takeuchi, 1973a, b, 1975). In an attempt to clarify further the factors governing the timing of the post-partum ovulation in rats, we have examined the effects of an oestrogen antagonist, clomiphene (see Labhsetwar, 1970), on the time of parturition and the post-partum ovulation.

Rats of the Wistar strain, bred in our own laboratory and kept in controlled lighting (lights on 06.00-18.00 hours), were used. Rats which had experienced three consecutive 4-day cycles were caged at pro-oestrus with fertile males and mating was verified by finding spermatozoa in the vaginal smear the following morning. This day was designated Day 1 of pregnancy.

Clomiphene citrate (Clomid: Sionogi Pharmaceutical Co. Ltd, Japan) was dissolved in $30 \%$ ethanol/saline and s.c. injected in a volume of $0.5 \mathrm{ml}$ at the times indicated in Table 1 . The animals were inspected at 09.00 hours each day and hourly after 12.00 hours on Day 21 of pregnancy to determine the time of parturition. The time of birth of the last young was designated as the time of parturition. The time of post-partum ovulation was determined by examining the oviducts, by phase-contrast microscopy for the presence of eggs, of rats killed 18, 24 or $30 \mathrm{hr}$ after parturition was completed.

Table 1. The numbers of rats giving birth on various days after the administration of $2.5 \mathrm{mg}$ clomiphene/rat on different days of pregnancy

\begin{tabular}{crrrrrrr}
\hline \multirow{2}{*}{$\begin{array}{c}\text { Day } \\
\text { of } \\
\text { treatment }\end{array}$} & $\begin{array}{c}\text { No. } \\
\text { of } \\
\text { rats }\end{array}$ & 20 & 21 & 22 & 23 & 24 & 25 \\
\cline { 2 - 7 } & 5 & & & & 4 & 1 & \\
15 & 5 & 2 & & & 3 & & 1 \\
17 & 6 & 1 & 2 & 1 & 1 & \\
18 & 14 & & 9 & 4 & 1 & \\
20 & 14 & 8 & & & 13 & 1 & \\
21 & 8 & & & & & 8 & \\
\hline
\end{tabular}

When $2.5 \mathrm{mg}$ clomiphene/rat was administered on various days from Days 15-21, treatment on Day 20 caused the most consistent premature onset of parturition. Examination of the hourly times of parturition showed that the majority ( $88 \%$ ) of rats treated with clomiphene on Day 20 (61) littered before the earliest of the normal rats in our colony (Hashizume et al., 1975), and that parturition was about $24 \mathrm{hr}$ in advance of the normal distribution.

The effects of different doses of clomiphene given on Days 19 and 20 are shown in Table 2. The most effective dose on either day was $5 \mathrm{mg} /$ rat but $2.5 \mathrm{mg} /$ rat was almost as effective on Day 20 .

The investigation of the timing of the post-partum ovulation after induction of premature parturition by treatment with $2.5 \mathrm{mg}$ clomiphene/rat on Day 20 showed that $6 / 23$ rats had ovulated within $18 \mathrm{hr}, 10 / 21$ within $24 \mathrm{hr}$ and $9 / 13$ within $30 \mathrm{hr}$. The mean ( \pm S.D.) numbers of eggs ovulated/ovulating rat were $4 \cdot 6 \pm 3 \cdot 3,3 \cdot 6 \pm 1 \cdot 8$ and $5 \cdot 2 \pm 3 \cdot 8$ respectively. There did not therefore appear to be a significant effect of clomiphene on the normal temporal relationship between parturition and the post-partum ovulation. 
Table 2. The numbers of rats giving birth prematurely after different doses of clomiphene on Days 19 or 20 of pregnancy

\begin{tabular}{|c|c|c|c|c|c|c|c|c|}
\hline \multirow{3}{*}{$\begin{array}{c}\text { Dose } \\
\text { (mg/rat) }\end{array}$} & \multicolumn{5}{|c|}{ Day 19} & \multicolumn{3}{|c|}{ Day 20} \\
\hline & \multirow[b]{2}{*}{ No. of rats } & \multicolumn{4}{|c|}{ Time after clomiphene $(\mathrm{hr})$} & \multirow[b]{2}{*}{ No. of rats } & \multicolumn{2}{|c|}{ Time after clomiphene (hr) } \\
\hline & & 48 & 72 & 96 & 120 & & 48 & 72 \\
\hline 0 (vehicle only) & 5 & & & 3 & 2 & 4 & & 4 \\
\hline 1.25 & 10 & 2 & 3 & 2 & 3 & 6 & 5 & 1 \\
\hline $2 \cdot 5$ & 14 & 9 & 4 & 1 & & 14 & 13 & 1 \\
\hline $5 \cdot 0$ & 4 & 4 & & & & 5 & 5 & \\
\hline $10 \cdot 0$ & 5 & 3 & 2 & & & 6 & 5 & 1 \\
\hline
\end{tabular}

Chatterjee, Gupta \& Sengupta (1974) have described the abnormal development of ovarian follicles in pseudopregnant and pregnant rats given clomiphene and attribute the termination of decidual growth and pregnancy in these animals to the associated increase in ovarian oestrogen secretion. Shaikh (1971) has reported a rapid increase in ovarian venous oestrogen concentrations in rats approaching term and Dukes, Chester \& Atkinson (1974) showed that administration of oestrogen on Day 21 of pregnancy advanced parturition in the majority of rats. It is possible, therefore, that the effect of clomiphene given on Day 20 is to cause increased gonadotrophin release leading to accelerated follicular development and a more rapid rise in oestrogen secretion during Day 21 and consequent early parturition. However, since clomiphene possesses both oestrogenic (Lerner, 1964) and anti-oestrogenic properties, this mechanism has yet to be confirmed.

\section{References}

Chatterjee, S., Gupta, T. \& Sengupta, K. (1974) Possible mode of action of clomiphene. I. Reversal of clomiphene-induced interruption of decidual growth and gestation by prolactin or progesterone in rats. Acta endocr., Copenh. 75, 173-180.

Dukes, M., Chester, R. \& Atkinson, P. (1974) Effects of oestradiol and prostaglandin $F$ on the timing of parturition in the rat. J. Reprod. Fert. 38, 325334.

Hashizume, K., Sugawara, S. \& Takeuchi, S. (1973a) Studies on the reproductive phenomena in the postpartum rat. I. Time of delivery and post-partum ovulation in rat. Tohoku J. agric. Res. 24, 117122.

Hashizume, K., Sugawara, S. \& TAKeuchi, S. (1973b) Studies on the reproductive phenomena in the postpartum rat. II. Ovulating hormone release in the post-partum ovulation in rat. Tohoku J. agric. Res. 24, 123-127.

Hashizume, K., Sugawara, S. \& Takeuchi, S. (1975) The follicular development and oocyte maturation with special reference to the release of ovulating hormone in post-partum rats. Jap. J. Anim. Reprod. 21, 28-36.

LABHSETWAR, A.P. (1970) The role of oestrogens in spontaneous ovulation: evidence for positive oestrogen feedback in the 4-day oestrous cycle. J. Endocr. 47, 481-493.

LERNER, L. J. (1964) Hormone antagonists: inhibitors of specific activities of estrogen and androgen. Recent Prog. Horm. Res. 20, 435-476.

SHAIKH, A.A. (1971) Estrone and estradiol levels in the ovarian venous blood of rats during the estrous cycle and pregnancy. Biol. Reprod. 5, 297-307.

Received 11 August 1975 